\title{
Tetralogy of Fallot Report of 30 Cases and Dental Considerations with Review of Literature
}

\author{
S Gedik ${ }^{1}$, R Gedik ${ }^{2}$, TN Gedik ${ }^{3}$
}

\begin{abstract}
Tetralogy of Fallot (TOF) is one of the most serious cyanotic congenital heart diseases and is characterized by common systemic and oral findings. This study was carried out on 30 patients (3-13 years old) with TOF and 30 subjects as a control group. The patients were examined for oral hygiene, mucous membrane, gingivae, dental caries and any hypoplasia. There appeared to be an increase in dental caries, hypoplasia and periodontal disease in the patients with TOF compared with controls. The dental aspects of TOF patients are highlighted and their dental management is discussed.
\end{abstract}

Keywords: Cyanotic congenital heart disease, dental caries, hypoplasia, periodontal disease, tetralogy of Fallot

WIMJ Open 2015; 2 (2): 102

\section{INTRODUCTION}

Tetralogy of Fallot (TOF) identifies a type of cyanotic congenital heart disease. The combination of obstruction to right ventricular outflow, ventricular septal defect, dextroposition of the aorta and right hypertrophy consitutes TOF (1, 2). The first anatomic description of TOF was by Stenson (3) in 1671; thereafter, Fallot (4) published his series of cases in 1888 describing four anatomic findings: pulmonary stenosis, dextroposition of the aortic origin, ventricular septal defect and hypertrophy of the right ventricle. However, the diagnosis of TOF was made by Taussig (5) during his work in the 1930s and 1940s.

The prevalence of TOF varies from clinic to clinic, depending on the age distribution in the clinic. The distribution between males and females is aproximately equal (2). The overall prevalence is $10 \%$ of all forms of congenital heart disease (6).

The exact aetiology is unknown in most cases, but the best known acquired cause is maternal rubella infection. The most striking feature of some types of congenital heart disease is cyanosis (7), when the deoxygenated blood is shunted from the right ventricle directly into the systemic circulation (right to left shunt). Among the most obvious clinical features are severe cyanosis and loud cardiac murmurs, paroxysms of cyanosis and breathlesness, which

From: ${ }^{1}$ Sivas Public Hospital Sivas, Turkey, ${ }^{2}$ Department of Oral Diagnosis and Radiology, Faculty of Dentistry and ${ }^{3}$ Faculty of Medicine, Cumhuriyet University, Sivas, Turkey.

Correspondence: Dr R Gedik, Department of Oral Diagnosis and Radiology, Faculty of Dentistry, Cumhuriyet University, 58140 Sivas, Turkey. E-mail: gedikrustu@gmail.com typically cause cerebral anoxia and syncope. Another characteristic is that these children tend to squat, particularly after exertion, to get some relief from breathlessness. The result of persistent hypoxia are poor physical development, clubbing of the fingers and toes and polycythaemia $(1,2,8-$ 13).

Oral abnormalities associated with TOF are cyanosis, which is most prominent in the mucous membranes of the lips and mouth and in the fingernails and toenails, delayed eruption of both dentitions and enamel hypoplasia (1, 1418). The dental management of these patients and prevention of infective endocarditis is very important $(1,7,15-19)$. The purpose of this article is to highlight the dental manifestations in patients with TOF. The prognosis of this disease has been enormously improved by cardiac surgery $(1,7)$.

\section{SUBJECTS AND METHODS}

This study was carried out at Hacettepe University Faculty of Dentistry on 30 patients (3-13 years old): 18 males and 12 females (mean age: 8.8 years) with TOF and 30 subjects as a control group: 13 males and 17 females (mean age: 5.6 years). The parents and patients were interviewed to obtain medical and dental histories, including information on preventive dental health behaviour and fluoride intake as well as prophylactic antibiotic cover for dental treatment. Further details of medical conditions were supplied by the cardiologist after the dental assessment. The dental and medical histories were recorded on examination forms.

Extraorally, the lips, fingernails, toenails, the entire skin and sclerae, and intraorally, the mucous membranes of the lips and mouth were examined. The mucous membranes 
of the pharynx, and the tongue, gums and teeth were also examined.

\section{RESULTS}

Cyanosis, one of the outstanding manifestations of TOF, may not be present at birth. Apparently, as long as the ductus arteriosus remains open, sufficient blood passes through the lung to prevent cyanosis. As it closes during the first months of life, cyanosis may become gradually apparent or develop suddenly when the infant has an infection $(1-7,20)$.

In the severe cases of TOF, the extraoral examination revealed prominent purple of the lips, fingernails and toenails. The sclerae were red, giving the appearance of mild conjunctivitis and there was severe finger clubbing. In moderate cases, the lips, fingernails and toenails were red and there was mild finger clubbing. The intraoral examination in severe cases revealed purple of the mucous membranes of the lips, the mouth and pharynx were purple, and the tongue was deep blue and often large and fissured, with prominent papillae. The gums were frequently inflamed and bled easily from light pressure. In mild cases, there was deep red of the mucous membranes of the lips, mouth and pharynx. The tongue was deep red and often large and fissured. The gums were frequently oedematous.

The extraoral examination of 30 TOF cases revealed that 17 cases $(56.6 \%)$ had severe cyanosis and clubbing, nine cases $(30 \%)$ had mild cyanosis and clubbing and in four cases $(13 \%)$, cyanosis and clubbing were not prominent (Figs. 14).

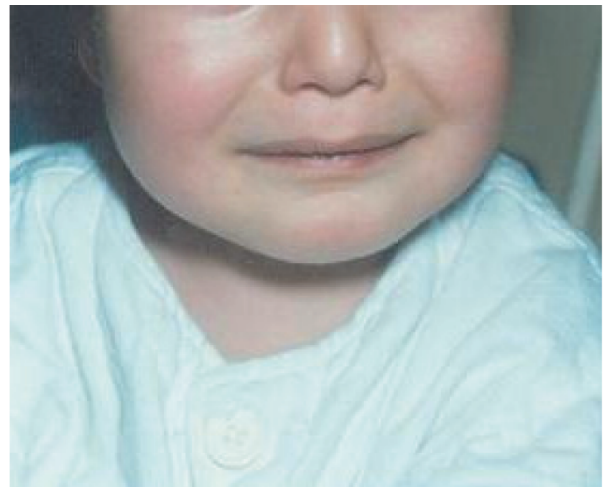

Fig. 1: Cyanotic lips in a child with tetralogy of Fallot.

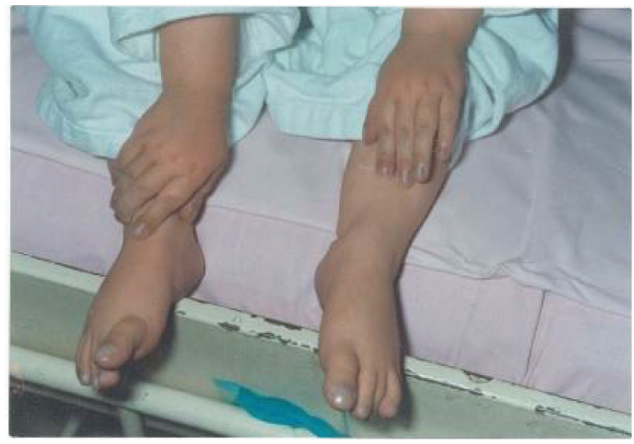

Fig. 2: Clubbing of digits in a child with tetralogy of Fallot.

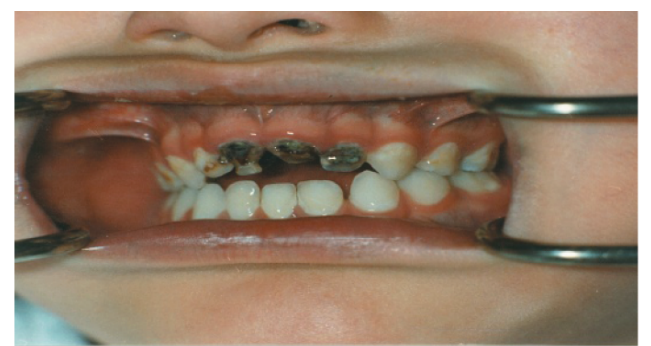

Fig. 3: Cyanotic gingivae and carious teeth in a child with tetralogy of Fallot.

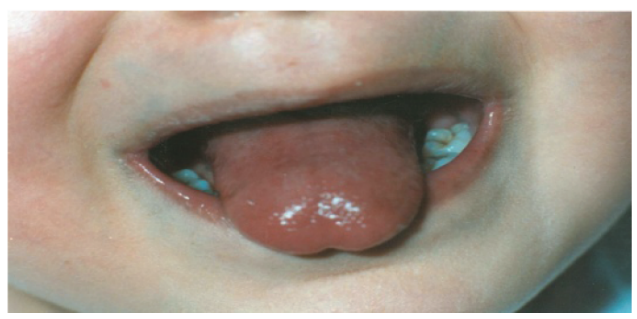

Fig. 4: Cyanotic tongue in a child with tetralogy of Fallot.

The intraoral examination of both groups in relation to the oral hygiene and gingival status revealed that 12 cases $(40 \%)$ of TOF had purple gingivae, 15 cases $(50 \%)$ were red and in three cases $(10 \%)$, there was no prominent change observed. Oedematous gingivae were seen in 24 cases (80\%) from 30 cases. The examination of the control group revealed that 24 cases $(80 \%)$ were normal and only six cases $(20 \%)$ had deep red gingivae. Oedematous gingivae were seen in only three (10\%) of 30 cases (Fig. 5).

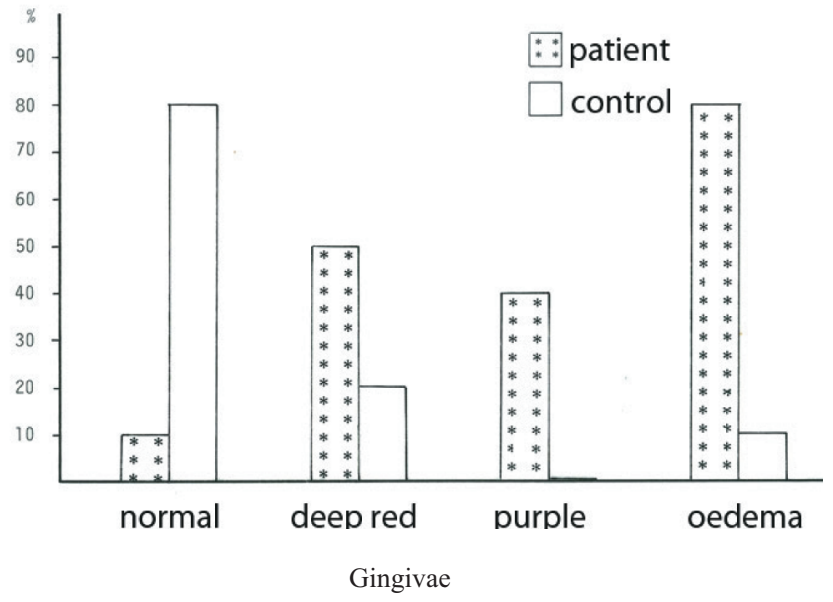

Fig. 5 Results of intraoral examination on gingival status.

The tongue was examined in both groups, which revealed that 12 cases of TOF had purple tongue (40\%), 15 cases $(50 \%)$ were deep red and in three cases $(10 \%)$, no prominent change was observed. The oedamatous tongue were seen in $22(73.3 \%)$ of 30 cases. The examination of the control group revealed that 24 cases $(80 \%)$ were normal and only six cases $(20 \%)$ had deep red tongue. The oedamatous 
tongue were seen only in four controls (13.3\%) of 30 cases (Fig. 6).

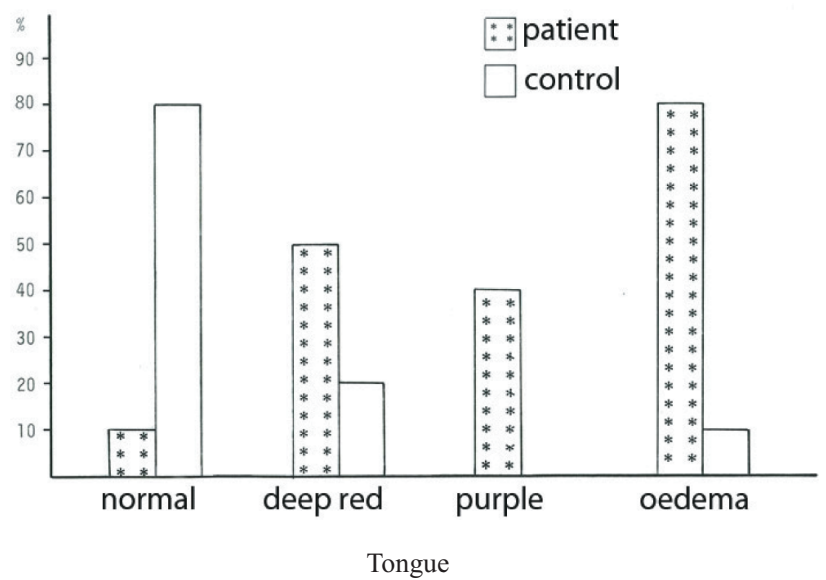

Fig. 6: Results of intraoral examination of the tongue.

The intraoral examination of both groups in relation to oral hygiene revealed that six cases $(20 \%)$ of TOF had good, 15 cases $(50 \%)$ mild and nine cases $(30 \%)$ bad hygiene. The examination of the control group revealed that 15 cases $(50 \%)$ had good, 12 cases $(40 \%)$ mild and three cases $(10 \%)$ had bad hygiene (Fig. 7). Gum bleeding by palpation was seen in six cases $(20 \%)$ of TOF patients, and one case $(3.34 \%)$ of the control group (Fig. 7).

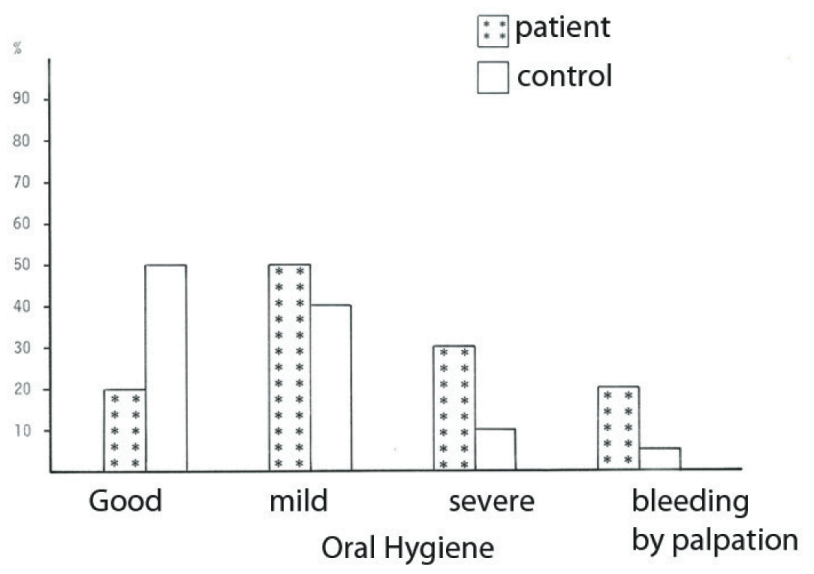

Fig. 7: Results of intraoral examination of oral hygiene.

The intraoral examination of both groups in relation to carious teeth and dental pain showed that the incidence of pain and carious teeth was higher among the TOF group compared with the controls.

\section{DISCUSSION}

In spite of the significance of TOF in dental management, little research has been conducted on the oral health of affected individuals (1-7). Kaner et al (11) reported that oral abnormalities associated with TOF are cyanosis - which is most prominent in the mucous membranes of the lips and mouth and in the fingernails and toenails - and delayed eruption of both dentitions, with an increased frequency of positional anomalies and enamel hypoplasia of teeth. Kutzleb (14) also reported cyanotic gingivae, tongue and lips in patients with TOF; this was backed up by Weymen (21). Forrester et al (18) reported that these patients had prominent cyanosis in the mucous membranes of the lips, tongue and mouth and there was digital clubbing. Nelson (1) also showed that prominent cyanosis was observed on the lips, mouth, pharynx, tongue, fingernails and toenails of these patients. Carranza (19) reported that these patients had prominent cyanosis in the mucous membranes of the lips and oedamatous fissural tongue.

In our study, only three cases $(10 \%)$ of TOF had no prominent changes observed in the gingivae and tongue. All other patients had mild to severe signs of TOF.

A higher prevalence of periodontal disease has been reported in patients with TOF $(7,13,17)$. Carranza (19) reported marginal gingivitis and periodontal destruction in such patients, while Kutzleb (12) reported stomatitis and periodontitis. Weymen (21) also observed periodontal destruction in these patients.

In our cases, periodontal destruction was not observed and only six patients $(20 \%)$ had bleeding on palpation.

Neil (14), Weymen (21), Sorenson (15) and Rosenthal and Fehler (16) have shown that children with TOF suffer poorer oral health. The results of our study back up these claims as only six cases $(20 \%)$ of TOF had good oral hygiene in comparison to half of the controls.

Relating to tooth decay and pain, Nelson (1) reported that the toothache which these patients suffered was related to pulpal engorgement. Research has shown that children with TOF also suffer from carious teeth $(8,11,14-16)$. Our study confirmed these results, as the incidence of carious teeth was higher among the TOF group compared with the controls.

A special hazard in some types of congenital heart diseases is the development of cerebral abcess. Far more important, however, are the risks of general anaesthesia and infective endocarditis through dental management $(7,8,20$, 21).

The following points should be considered in the dental management of patients with TOF (22):

- a thorough medical history should be taken

- treatment should be done under stress-free conditions in conjunction with behaviour management techniques

- premedication with anti-anxiety drugs is necessary to reduce anxiety

- uncooperative children can be managed with conscious sedation or general anaesthesia

- antibiotic prophylaxis is indicated for procedures like deep scaling, minor surgical procedures and 
restorative procedures involving clamping and banding

- the patient's mouth should be rinsed with $0.2 \%$ chlorhexidine gluconate to reduce bacterial count before a procedure

- during a hypercyanotic attack, place the patient in the knee-chest position, administer oxygen of 0.2 $\mathrm{mg} / \mathrm{kg}$ body weight or refer to a physician

\section{CONCLUSION}

There appears to be an increase in dental caries, hypoplasia and periodontal disease in patients with TOF compared to controls. The prognosis of this disease has been enormously improved as a result of cardiac surgery.

\section{REFERENCES}

1. Behrman RE, Vaughan VC III, eds. Nelson textbook of pediatrics. Philadelphia: WB Saunders Co; 1983: 660-1026.

2. Adams FH, Emmanouilides GC, eds. Moss' heart disease in infants, children and adolescents. $3^{\text {rd }}$ ed. Baltimore: Williams \& Wilkins; 1983 $118-215$.

3. Stensen N. Quoted by Goldstein HI. In: Discussion of Jarcho S: Giovanni Battista Morgagni. Bull Hist Med 1948; 20: 526.

4. Fallot EA. Contribution a l'anatomie pathologique de la maladie bleue (cyanose cardiaque). Marseilles Med 1888; 25: 77, 138, 207, 270, 341, 403.

5. Taussig HB. Congenital malformations of the heart. $2^{\text {nd }}$ ed, vol 2 . Cambridge: Harvard University Press; 1960: 3-10.

6. Kieth JD, Rowe RD, Vlad P. Heart disease in infancy and childhood. $3^{\text {rd }}$ ed. New York: MacMilan; 1978.

7. Scully C, Cawson RA. Congenital heart disease. In: Scully C, Cawson RA, eds. Medical problems in dentistry. $4^{\text {th }}$ ed. Mumbai: KM Varghese; 1998: 69-71.

8. Berger ENH. Attitudes and preventive dental health behaviour in children with congenital cardiac disease. Aust Dent J 1978; 23: 87-90.

9. Rockman RA. Tetralogy of fallot: characteristcs, dental implications and case study. ASDC J Dent Child; 1989 56: 147-50.

10. Moncrieff AA, Evans P. Diseases of children. In: Tizard JPM. The environmental causes of congenital malformation. $3^{\text {rd }}$ ed. London: Edward Arnold; 1953: 43-61.
11. Kaner A, Losch PK, Green H. Oral manifestation of congenital heart disease. J Pediatrics 1945; 29: 269-74.

12. Kutzleb HJ. Paradentale verandarungen bei der sogenannten. Blauscht Dtsh Zahnarzt Z 1955; 11: 857-9.

13. Gould MSE, Picton DCA. The gingival condition of congitally cyanotic individuals. Br Dent J 1960; 109: 96-109.

14. Neil CA. Tetralogy of Fallot. In: Gellis SS, Kagan BM, eds. Current pediatric therapy. Philadelphia/Toronto: WB Saunders Co; 1968: 190-194.

15. Sorenson HW. The pedodontic patient with heart disease. Dent Clin North Am 1973; 17: 173-8.

16. Rosenthal A, Fehler DC. General principles in the treatment of congenital heart disease. In: Gellis SS, Kagan BM, eds. Current pediatric therapy. Philadelphia/London/Toronto: WB Saunders Co; 1976: $138-139$.

17. Gidding SS, Rosenthal A. The interface between primary care and pediatric cardiology. Ped Clin N Amer 1989; 31: 1367-74.

18. Forrester DJ, Wagner ML, Fleeming J. Pediatric dental medicine. Dental care of the handicapped child. Philadelphia: Lea and Febiger; 1981: 613-6.

19. Carranza FA. Glickman's clinical periodontology. $7^{\text {th }}$ ed. Philadelphia: WB Saunders Co; 1990: 469-470.

20. Nadas AS. Update on congenital heart disease. Pediatr Clin North Am 1984; 31: 153-64.

21. Weymen J. The dental care of handicapped children. Edinburg and London: Churchill Livingstone; 1971: 40-45.

22. Babaji P. Tetralogy of Fallot: a case report and dental considerations. Rev Clin Pesq Odontol 2009; 5: 289-92.

Received 01 Oct 2014

Accepted 29 Oct 2014

Revised 03 Feb 2015

Published 29 May 2015

Online: http://www.mona.uwi.edu/wimjopen/article/1644

(C) Gedik et al 2015

This is an open access article made freely available under Creative Commons Attribution 4.0 International (CC BY 4.0). Users are free to share, copy and adapt this work as long as the copyright holder (author) is appropriately and correctly credited. See http://creativecommons.org/ licences/by/4.0/deed.en_us for more information. 